\title{
Los fondos de Responsabilidad Social Empresaria minera como sostén económico de políticas públicas. La experiencia de la Fundación Agencia de Desarrollo San Julián, Patagonia Argentina \\ Mining Corporate Social Responsibility Funds as Economic Support for Public Policies: The Experience of the San Julian Development Agency Foundation, Patagonia, Argentina
}

María Gabriela Aguilar

Copyright: @ 2021

Revista Internacional de Cooperación y Desarrollo. Esta revista proporciona acceso abierto a todos sus contenidos bajo los términos de la licencia creative commons Atribución-NoComercial-SinDerivar 4.0 Internacional (CC BY-NC-ND 4.0)

Tipo de artículo: Resultado de Investigación

Recibido: enero de 2021

Revisado: marzo de 2021

Aceptado: abril de 2021

\section{Autores}

1 Magíster en Economía. Docente e Investigadora. Universidad Nacional de la Patagonia Austral (UNPA). Becaria Doctoral Consejo Nacional de Investigaciones Científicas y Técnicas (CONICET).

Correo electrónico: aguilar.gabriela@conicet.gov.ar Orcid: https://orcid.org/0000-0003-1172-6619

\section{Cómo citar:}

Aguilar, M. (2021). Los fondos de Responsabilidad Social Empresaria minera como sostén económico de políticas públicas. La experiencia de la Fundación Agencia de Desarrollo San Julián, Patagonia Argentina. Revista Internacional de Cooperación y Desarrollo. 8(1), 78-94

DOI: $10.21500 / 23825014.5210$

\section{G OPEN ACCESS}

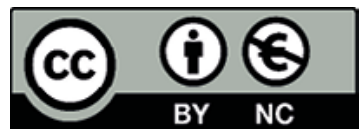

\section{Resumen}

En este artículo se analiza el rol que ejerce la Fundación Agencia de Desarrollo Local (FADL) en una pequeña localidad de la provincia de Santa Cruz; Puerto San Julián, que es área de influencia del yacimiento metalífero Cerro Vanguardia; al sur de Argentina. Establecida en 2004, la FADL es una institución promovida por el gobierno local y la empresa minera Cerro Vanguardia SA, que la sostiene económicamente mediante los aportes de Responsabilidad Social Empresaria (RSE). Tras identificar el destino de los aportes, planes y convenios firmados, se analiza si los objetivos para los que fue constituida han sido ejecutados.

Palabras clave: responsabilidad social; minería; desarrollo participativo; política gubernamental; San Julián.

\section{Abstract}

This article analyzes the role of the Local Development Agency Foundation (FADL) in a small town in the province of Santa Cruz; Puerto San Julián, which is the area of influence of the El Cerro Vanguardia metal deposit, in the south of Argentina. Established in 2004, the FADL is an institution promoted by the local government and the El Cerro Vanguardia S.A. mining company, which supports it financially through contributions from Corporate Social Responsibility (CSR). After identifying the destination of contributions, plans, and agreements signed, it is analyzed if the objectives for which it was established have been executed.

Keywords: Social Responsibility; Mining; Participatory Development; Government Policy; and San Julián. 


\section{Introducción}

En este artículo se analiza el rol que ejerce la Fundación Agencia de Desarrollo Local (FADL) en una pequeña localidad de la provincia de Santa Cruz: Puerto San Julián, que es área de influencia del megaproyecto minero a cielo abierto Cerro Vanguardia, al sur de Argentina. Establecida en el año 2004, la FADL es una institución público-privada; conformada por diversos actores, y promovida por el gobierno local y por la empresa minera Cerro Vanguardia SA (CVSA), que la sostiene económicamente mediante los aportes anuales de Responsabilidad Social Empresarial (RSE).

Este artículo postula que la FADL fue instituida desde la empresa minera con la finalidad de obtener consenso e integración con la sociedad sanjulianense, generando a su vez una imagen positiva de la minería a cielo abierto, por medio de la asignación de fondos de RSE para la localidad, promocionándola desde la propia FADL como la incubadora y hacedora del motor del desarrollo local para un próximo Puerto San Julián sin minería, estimando el 2020 como año de cierre de mina. ${ }^{1}$ En este caso, el futuro de la localidad ya no dependería de la multinacional, sino del uso de los fondos que hubieran hecho los decisores del gobierno y del directorio de la FADL (gran parte de ellos pertenecientes a cargos políticos); con el objetivo de generar desarrollo económico sustentable, mediante la implementación de programas de políticas públicas. Se busca así, analizar los objetivos propuestos a desarrollar por la institución en su Plan Participativo, y si la misma ha cumplido con la finalidad para la que fue creada.

\footnotetext{
'En la página web de la propia empresa dice: "En el año 2004, pensando en la idea que en un futuro no muy lejano se produciría la desaceleración de la actividad minera generada por "CVSA", por tratarse de la extracción de recursos no renovables, es que la Compañía propuso la creación de un ente en Puerto San Julián, que se ocupe de impulsar el desarrollo de actividades económicas sustentables". Ver en: www. cerrovanguardia.com.ar/responsabilidad-social/relato-historico-sobre-la-agencia/. Según el Estatuto de la FADL como en su página web se describe: "La Fundación Agencia de Desarrollo es un espacio institucional de concertación Público/Privada que impulse el crecimiento de la región". (Fundación Agencia Desarrollo, 26/06/2006) http://agenciadesarrollosj.gob.ar/quienes-somos/
}

La participación del gobierno local en el uso de los fondos de RSE de la FADL es necesaria para llevar adelante cualquier acuerdo o gestión que tenga que ver con el empleo de los mismos; ya que el Municipio es quien recibe los aportes y luego los destina a la institución designada, ya sea mediante la firma de un Acuerdo o realizando la compra requerida a través de los mecanismos de concurso público o licitaciones, interviniendo los Departamentos y Secretarías correspondientes.

Gran parte de la investigación sobre la minería en la Patagonia se ha centrado en los movimientos sociales (Svampa, 2008; Antonelli, 2009) y los cambios socio-productivos producidos en torno al modelo de desarrollo basado hasta ese entonces, en la ganadería intensiva exportadora (Andrade, 2005). Algunos trabajos más recientes abordan la temática de la minería en Santa Cruz analizando las consecuencias socioeconómicas que trae la explotación del proyecto Cerro Vanguardia en la comunidad de Puerto San Julián y la actuación de la FADL y de los gobiernos local y provincial (Andrade et al, 2011); (Torunczyk Schein, $2015,2016)$ y Bechtum (2018). Antonelli (2009) analiza el discurso de la minería responsable en el marco del desarrollo sustentable ${ }^{2}$ mediante un modelo de RSE similar al de la FADL, un modelo de triple hélice que enlaza a Empresa, Estado y Comunidad:

La RSE forma parte del declarado "cambio cultural", para responder proactivamente a la más que negativa reputación de la industria en el mundo y a la creciente conflictividad y resistencia a esta explotación. Tal res-

\footnotetext{
2 El concepto de "desarrollo sustentable" se remite a 1983 cuando fue creada la Comisión Mundial sobre Medio Ambiente y Desarrollo (CM$M A D)$, en la XXXVIII Sesión de la ONU, por resolución de la Asamblea Ceneral. De su trabajo surgió el documento conocido como Nuestro futuro común (o Informe Brundtland), que parte de la idea central de que desarrollo y medio ambiente no pueden ser separados. El DesarroIlo Sustentable es el modelo de desarrollo que aspira a incrementar la cantidad de bienes y servicios disponibles en una sociedad bajo la condición de que los mismos sean distribuidos con creciente equidad, a fin de superar las desigualdades sociales estructurales y eliminar la pobreza incorporando el medio ambiente. El mismo debe satisfacer las necesidades de la presente generación sin comprometer la capacidad de las futuras generaciones para que satisfagan sus propias necesidades Esta propuesta adquiere status universal en la declaración de cierre de la Conferencia de Río de Janeiro, celebrada en 1992 (Rofman, 2004).
} 
ponsabilidad se configura como un modelo de "triple hélice": ambiental, económica y social, cuya dinámica enlazaría a empresas, Estado y comunidad como lazo ético-filantrópico para el desarrollo. En su base se postula la "transparencia" como distintiva de esa dinámica, por lo que reserva para sí la posibilidad de articular al Estado como garante-contralor $y$, por tanto, corresponsable de la industria, a la vez que se explicita la responsabilidad transparente y la transparencia responsable como justificativo de la teatralidad: el despliegue de las profusas prácticas a nivel local-comunitario en instituciones y ámbitos asociados precedentemente al Estado (escuelas, hospitales, dispensarios, taIleres comunitarios, etc.), la implementación de campañas de presencia de la minera en eventos, efemérides, celebraciones, etc., de la comunidad, y fuertes inversiones publicitarias en los medios locales. Estas estrategias engarzadas ponen en escena, para ser vistas y recordadas, las performances de la responsabilidad empresarial y sus afectos públicos (pp. 76-78).

En el discurso de las empresas la RSE debe fomentar junto al Estado y a la Comunidad, el desarrollo sustentable de la sociedad donde se asienta. El enfoque de desarrollo propiciado desde el Plan Participativo de San Julián y de la FADL, en conjunto con el gobierno, es similar a la perspectiva que ofrece el neoestructuralismo. Es decir la búsqueda de una articulación de las posibilidades de desarrollo socioeconómico a partir de la explotación de recursos naturales. Peinado y Saguier (2014) señalan en relación a este enfoque que el desarrollo es entendido como cambio cualitativo en el plano económico y social, concibiendo este último como transformaciones positivas en el mercado de trabajo. La visión neoestructuralista se basa en el principio de sustentabilidad débil, como capacidad del sistema económico de sustentarse en el tiempo a partir de un aprovechamiento de los excedentes generados por la actividad minera. Así, las obras de infraestructura (capital manufacturado), la inversión en educación (capital humano) y el desarrollo de encadenamiento hacia atrás como fuentes de generación de empleos de alta productividad (y por lo tanto de mayores salarios), tenderían a compensar las reducciones en la dotación de recursos minerales metalíferos.

Mediante el uso de argumentos teóricos citados (Antonelli, 2009; Torunczyk Schein, 2015, 2016; Bechtum 2018; Andrade et al, 2011, Peinado y Saguier, 2014), este artículo se propone analizar la función de la FADL en la localidad de Puerto San Julián como receptora de los fondos de la política de RSE de CVSA y su misión de fomentar planes y proyectos de desarrollo económico, acompañada por el gobierno local en el diseño e implementación de las políticas públicas dirigidas a ello. ${ }^{3}$

Los interrogantes que se plantean son: ¿Cómo afectan los fondos de RSE que CVSA otorga a la FADL en la ejecución de políticas públicas que lleva adelante el Estado local? De acuerdo con los objetivos establecidos en la creación de la FADL y en el Plan Participativo "San Julián piensa 2020", ¿qué destino han tenido los fondos de RSE en San Julián? A casi diecisiete años de su fundación, ¿se han implementado los programas y proyectos asociados a ese Plan que buscaban promover la diversificación económica e inversión en otras actividades económicas?

En primer lugar, se identifican los factores políticos y económicos que en los años noventa favorecieron la puesta en marcha de Cerro Vanguardia. En segundo lugar, se analiza por qué tras varios años de explotación del proyecto Cerro Vanguardia, se institucionaliza este nuevo actor, la FADL. Por último, se realiza la identificación dentro del Plan Participativo "San Julián piensa 2020", de las propuestas y de los principales ejes planificados y a desarrollar con los fondos de la FADL; confrontando cuales de esas propuestas se han ejecutado hasta la actualidad y si finalmente se han cumplido los objetivos que se plantearon para el 2020.

\footnotetext{
Bertranou (2019) señala que: "las políticas públicas representan flujos de prácticas dirigidas intencionalmente a la resolución de algún problema. Son el principal instrumento que tienen los gobiernos para resolver las cuestiones que han problematizado, sin que esté garantizado a priori un resultado favorable" (p.152)
} 


\section{Metodología}

Este artículo se basa en el análisis de fuentes documentales de la FADL, tales como el Plan Participativo "San Julián piensa el 2020", el Testimonio del Estatuto Social de la FADL; como también en todos los Acuerdos Anuales de Responsabilidad Social Empresaria firmados entre la empresa CVSA, el Municipio y la Fundación Agencia de Desarrollo desde el año 2010 al 2019 con los aportes respectivos direccionados a determinados proyectos o desarrollos decididos por el Directorio, que han sido brindados por la misma Fundación. También se tuvieron en cuenta en el desarrollo de la investigación, los artículos anteriores escritos sobre el tema y fuentes periodísticas.

\section{Proyecto Cerro Vanguardia y Puerto San Julián}

En Argentina, con la sanción de la Ley 24.196, a partir de 1993 se otorgaron condiciones beneficiosas en materia impositiva y de seguridad en las inversiones mineras, constituyendo junto al Código de Minería, las bases del marco jurídico. A través de esta Ley, las provincias tienen derecho a establecer regalías entre el 1 y el $3 \%$ sobre el valor "boca mina" ${ }^{4}$ del mineral extraído (Godfrid, 2015); reservándose además el derecho de dictar las Autoridades de Aplicación de la legislación minera, en lo referido tanto a la cuestión de regalías como al impacto ambiental. Se concede a los inversores mineros una estabilidad fiscal durante treinta años (a partir del estudio de factibilidad), se otorgan beneficios respecto del impuesto de las ganancias (deducción del 100\% de los montos invertidos), y se exime a las empresas del pago de derechos a la importación. Igualmente se promulga en 1995, la Ley de Actualización Minera (24.498), eliminándose con ella, tanto la exclusividad del Estado para la explotación del recurso como las áreas de reserva para empresas públicas (Huwiler, Duarez, Codfrid, 2015).

\footnotetext{
${ }^{4}$ Se define como el valor de los minerales declarados por el productor minero como el valor obtenido en la primera etapa de su comercialización, menos los costos directos y/u operativos.
}

En Santa Cruz, la llegada de la gran minería viene de la mano de Néstor Kirchner, quien ocupó el poder ejecutivo de la provincia desde 1991 hasta 2003. El pulso político a favor de la minería se visualiza con la promoción de la empresa estatal Fomento Minero Santa Cruz (FOMICRUZ), que se convertirá en un actor fundamental en la explotación en sociedad con el capital nacional-transnacional, ya que es la propietaria de una amplia cartera de yacimientos petroleros y mineros. Por otro lado, el estímulo socioeconómico, viene dado por el declive del sector ganadero en los años noventa, con poca competitividad y bajos precios de la lana, y con zonas de producción devastadas por la presencia de cenizas procedentes del volcán Hudson de Chile, como la Meseta Central, donde se encuentra Puerto San Julián (Torunczyk, 2015, Andrade, 2005), y en el que precisamente se pondrá en marcha el primer proyecto de la gran minería en Santa Cruz.

La gran minería se añadiría como un nuevo elemento dinamizador de la economía extractiva y rentística santacruceña, que se ha ido conformando desde mediados de siglo con las rentas que obtiene la provincia mediante la explotación petrolera y de gas. "Santa Cruz asume un perfil de carácter subsidiador, con una economía que gira en torno de la redistribución estatal de los ingresos percibidos por regalías petroleras" (Schinelli, Vacca, WiIliams, 2011, p. 38).

En el año 1990 la empresa estatal FOMICRUZ adjudica a la empresa Minera Mincorp S.A la prospección y exploración con derecho a opción para la explotación, del prospecto Cerro Vanguardia. La exploración inicial se extendió hasta 1996, culminado con el estudio de factibilidad, y compensado con la estabilidad fiscal por treinta años que otorgaba la Ley de Inversiones Mineras. Ya en etapa de producción, a finales de 1996 se reestructuró convirtiéndose en Cerro Vanguardia S.A. (CVSA) e incorporando a FOMICRUZ como socia accionaria del 7,5\% y reteniendo AngloCold Ashanti y Pérez Companc el 46,25\% cada una. En el año 2002, AngloCold Ashanti adquirió la participación de Pérez Companc, pasando a retener el $92,5 \%$ de las acciones. ${ }^{5}$

\footnotetext{
${ }^{5}$ Más información en http://miningpress.com/club/266805/cerro-vanguardia-mas-de-20-anos-juntos, consultado el 28 de diciembre, 2020
} 
Puerto San Julián, se convertía así en la localidad de influencia del Yacimiento. En el proceso de despliegue del proyecto, la población no ejerció oposición a la actividad minera; probablemente la distancia del yacimiento respecto a la localidad que se sitúa en torno a unos $150 \mathrm{~km}$, o la posibilidad de encontrar trabajo pueden haber sido las causantes. O simplemente, el recelo que tienen los ciudadanos de perder beneficios que les han sido otorgados por el gobierno y que condicionan a la ciudadanía a no participar de los procesos de decisión o consulta, que en este caso ni siquiera existieron. Como señala Svampa (2008), "estos emprendimientos suelen encontrar un contexto favorable en aquellas regiones caracterizadas por una matriz social jerárquica y escasamente diversificadas desde el punto de vista económico, donde imperan gobiernos provinciales y municipales de bajísima calidad institucional y sobreabunda el empleo estatal" (p. 22).

El proyecto había sido promocionado por la empresa AngloGold Ashanti como una alternativa económica para gran parte del pueblo que se encontraba sin empleo (el índice oficial del INDEC en 1991 arrojaba 5,2\% de personas desocupadas y se estimaba que para mediados de esa misma década la desocupación superaría el 20\%). Al inicio solo pocos habitantes de la localidad tuvieron la posibilidad de conseguir un trabajo en la empresa minera, gran parte de los contratados procedían de otras localidades, ya sea porque tenían formación universitaria referente a la minería, o porque eran obreros que estaban habituados a trabajar bajo regímenes petroleros de jornadas extensas. (Torunczyk, 2015).

Puerto San Julián inició un proceso de crecimiento de población. Las comparaciones intercensales dan cuenta del incremento según datos del Instituto Nacional de Estadísticas y Censos (Indec, s.f), ${ }^{6}$ pasando de poco más de 5000 habitantes en 1991 a más de 6200 en 2001, y en 2010 a 9200 personas. Las estimaciones más recientes ubican la población en alrededor de 17 000; en 2018, según el relevamiento socio-ocupacional y demográfico realizado por la Universidad Nacional de

${ }^{6}$ Para mayor información ver: https://www.indec.gob.ar/indec/web/ Nivel3-Tema-2-41 la Patagonia Austral (UNPA) (Andrade, 2018), el porcentaje de población acumulado en los últimos veinte años es superior al $70 \%$, por lo cual cobran sentido las especulaciones acerca del número real de población en la ciudad (aproximadamente 17 o०o). En el relevamiento se señala también que la mitad de la población que hoy habita en la ciudad de Puerto San Julián es nacida en la misma y que prácticamente el $80 \%$ de los encuestados arribó hace veinte años o menos, lo que coincide, por un lado, con la migración rural-urbana producto de la crisis de la ganadería ovina extensiva y, por el otro, con el arribo de la gran minería transnacional a la provincia. El marco social se vio modificado por la presencia de migraciones internas y de países limítrofes.

Respecto a las ocupaciones, muchos de los habitantes locales trabajan directa o indirectamente vinculados con la actividad minera, otros esperando poder hacerlo y otros tantos trabajaron en la etapa de construcción de la planta y hoy realizan actividades de diversa calidad, siendo características de estas ocupaciones la inestabilidad, la baja remuneración y la ausencia de cobertura y apoyos sociales (Andrade et al, 2011).

Mediante un plano de la Dirección de Proyecto y Planificación del Municipio se refleja el crecimiento del ejido urbano desde el año 2004 al 2015. En el mismo, se puede apreciar como aumentó la zona construida, con viviendas privadas y barrios públicos, que además implicó inversiones en infraestructuras tales como colegios públicos, ampliación del hospital, gimnasios, plazas, entre otros. 


\section{CRECIMIENTO TEJIDO URBANO}

\section{desde 2004 hasta 2015}

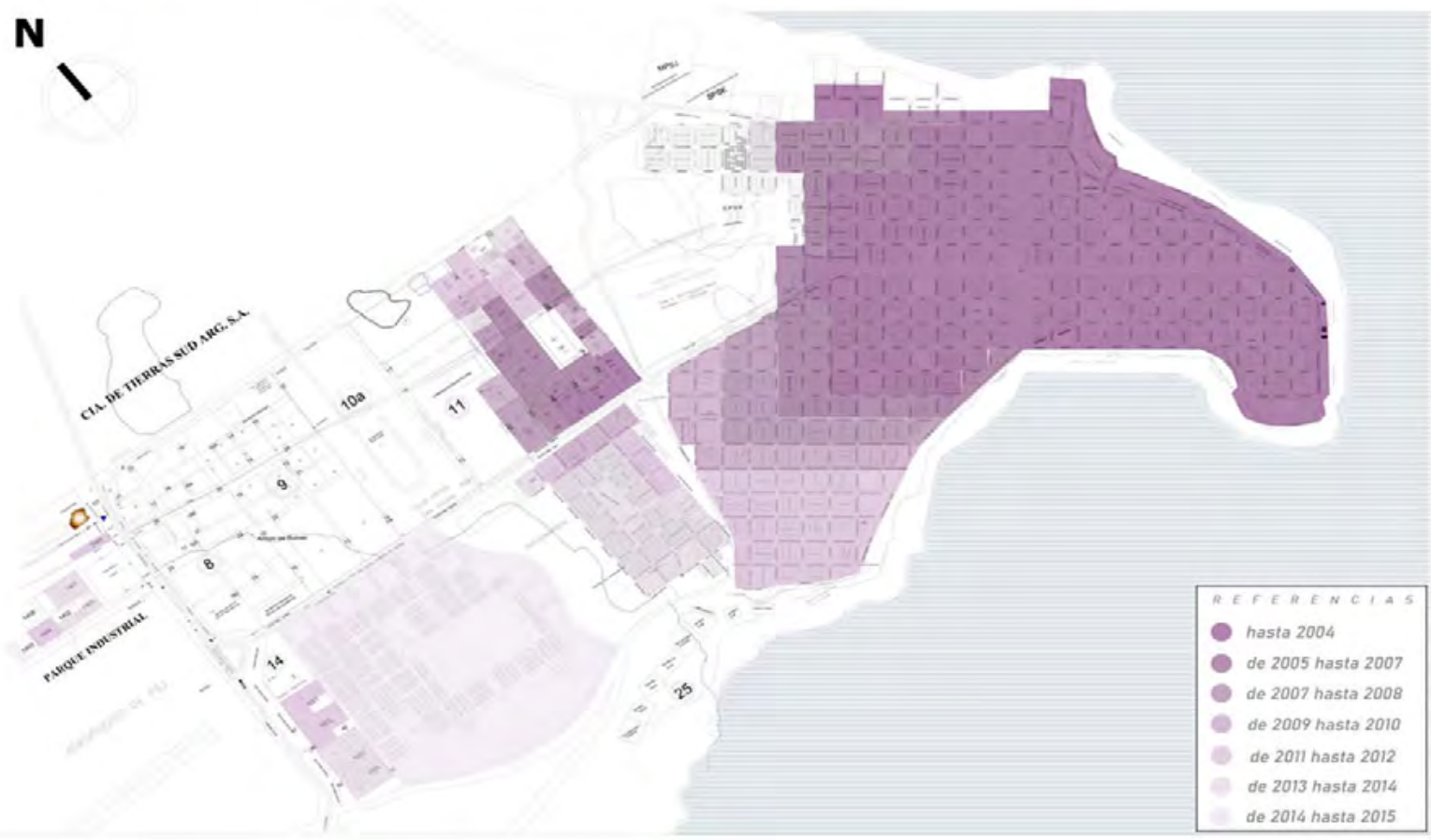

Fuente: Dirección de Proyecto y Planificación Municipalidad de Puerto San Julián (2021).

\section{Resultados}

A. El Plan Participativo, sus objetivos y resultados

El enfoque de la RSE en la gestión de los negocios es moderno. Según la Cepal (2006):

Algunos autores en los años ochenta dieron origen a la teoría de los stakeholders (partes interesadas), que presenta a las empresas como un sistema relacionado con la sociedad y, en consecuencia, obligada a rendir cuentas a las personas, las instituciones, los grupos y las comunidades. Estos stakeholders son impactados (directamente o indirectamente) por la empresa y ésta, a su vez, puede verse influida por aquéllos. El Comité para el Desarrollo Económico dio un giro fundamental a la RSE sosteniendo que es la sociedad quien proporciona a la empresa la posibilidad de operar y que, por lo tanto, la empresa tiene la obligación de satisfacer las necesidades de dicha sociedad (p. 7).
La RSE se extendió a partir de los años 2000, promovida por los organismos internacionales como la Organización de Naciones Unidades y el Banco Mundial, y en el sector minero por el Internacional Council On Mining \& Metales (ICMM) que fue creado en el marco de la Cumbre de la Tierra en 2001. Las políticas tienen un carácter voluntario y les permiten a las empresas mineras posiciones como promotores del desarrollo sustentable (Antonelli, 2009; Betchum 2018).

Como señala Bechtum (2018), "desde el comienzo de la explotación, la operadora transnacional intervino en diferentes ámbitos sociales y espacios públicos de San Julián, como el sector educativo y de la salud que tradicionalmente son de dominio estatal en Argentina" (p. 164). El cambio que da la empresa en cuanto a su política de RSE es una respuesta estratégica y de anticipación ante una posible emergencia de conflictos con la población, y tiene que ver con lo sucedido en 2003 en otra ciudad patagónica, Esquel, donde grupos de ciudadanos, mediante asambleas 
y manifestaciones lograron prohibir la minería a cielo abierto, con gran cuestionamiento social hacia la actividad. Por ello, tras ocho años de explotación minera, en junio de 2004, con el impulso de la empresa minera CVSA, los principales actores institucionales de la localidad de Puerto San Julián junto con el gobierno local y provincial crean una Agencia de Desarrollo, que promete orientar sus estrategias hacia el desarrollo sustentable.

El 20 de diciembre de 2006 a propuesta de la Agencia, se firmó el "Acta-Compromiso de Responsabilidad Ciudadana y de Cooperación para la Planificación Estratégica y Participativa del DesarroIlo Sustentable de Puerto San Julián y su zona de influencia", entre la Municipalidad de San Julián, el Honorable Concejo Deliberante, los bloques políticos y la Agencia de Desarrollo. La firma del Acta recibió la adhesión de treinta y ocho organizaciones públicas, privadas y de la sociedad civil de San Julián, acordando que la Agencia de Desarrollo sería el ámbito organizacional operativo del Plan Participativo de Desarrollo Sustentable de Puerto San Julián y su zona de influencia y así nace: "2007-San Julián piensa San Julián-2020”7 (Cerro Vanguardia, 2020).

Esta acción le dio la base legal al proceso de planificación y el compromiso institucional mínimo para su sustento, poniendo en marcha el proceso interinstitucional, interdisciplinario y participativo ${ }^{8}$ para planificar estratégicamente el desarrollo sus-

\footnotetext{
7 Sobre el Plan Participativo: www.cerrovanguardia.com.ar/responsabilidad-social/como-construimos-el-plan-participativo-de-desarroIlo-sustentable

${ }^{8}$ El concepto de participativo podemos entenderlo según describe la Cepal: "El concepto de participación ciudadana está íntimamente ligado al del poder. Hoy, quienes tienen el poder para participar de la vida política son las autoridades y los que ocupan cargos de representación popular, que han obtenido a través del voto que les ha dado la ciudadanía. Es un poder delegado de la ciudadanía soberana a través de las elecciones como medio legítimo. Al ampliar el campo de la política e involucrar a otros actores interesados en los temas públicos, este poder se distribuye entre más actores presentes en el debate. Por esto se dice que la participación es la lucha por el reconocimiento de los derechos y por tener una cuota de poder que permita ser reconocido como un otro legítimo en este debate público y en su proceso de toma de decisiones. Una de las principales formas de fortalecer la calidad de la democracia es lograr que la ciudadanía se involucre y tome parte en los temas públicos" (Cepal, 2015, p. 16).
}

tentable de San Julián y su zona de influencia hacia el año 2020. Para la gestión del proceso, la Agencia contrató a un equipo de profesionales que asumió la responsabilidad técnica del mismo, con un Coordinador Ceneral y un Asistente Técnico. Para tal fin, se subscribió un Protocolo Adicional al Convenio Marco firmado con la UNPA, formalizando la participación de sus profesionales en el Plan Participativo.

En junio de 2008, la misma Agencia entrega a la comunidad y al Estado Municipal el Plan Participativo de Desarrollo Sustentable de Puerto San Julián y su Zona de Influencia "San Julián piensa San Julián 2020" (PPDSPSJyZI) (Mansilla, 2014). El PPDSPSJyZI se organizó en torno a dieciséis áreas estratégicas que se correspondieron con las directrices de desarrollo institucional, desarrollo productivo-social, desarrollo medioambiental y de ordenamiento territorial. El objetivo del Plan Participativo consistió en investigar cuáles eran las necesidades de la localidad, incluyendo aspectos económicos, culturales, sociales e institucionales. Durante dos años se organizaron talleres sectoriales, foros y mesas redondas para promover el debate entre la comunidad y técnicos-expertos acerca de las necesidades en cada área estratégica.

Algunos de estos ámbitos se constituyeron en torno a cada área estratégica del Plan. En cada una de estas instancias, abiertas a la ciudadanía, participaron tanto vecinos, en representación propia o de las instituciones locales, como los funcionarios del Estado municipal y provincial. "A lo largo del proceso más de trescientas personas participaron de estos espacios, más de cuatrocientas fueron encuestadas o entrevistadas y más de cien acercaron sus opiniones y reflexiones de modo informal y anónimo" (Mansilla, 2014, p. 139).

Desde la perspectiva del Plan Participativo, publicado en la web de la FADL, en el informe final se analizó la percepción de los ciudadanos sobre las inversiones y sus efectos en la comunidad, teniendo en cuenta su sustentabilidad y los beneficios que generan a largo plazo. Entre las actividades propuestas o valoradas como positivas, se destaca el desarrollo de la actividad industrial y un mayor desarrollo 
del turismo. Estas actividades, combinadas con la minería y otras actualmente en funcionamiento, cuyo crecimiento y actividad actual no se ve como una amenaza o problema, requieren que generen beneficios perdurables en el tiempo. Se señala en el informe que para el caso de la minería existe una necesidad de establecer algunas pautas para que la comunidad obtenga beneficios a largo plazo de esta actividad, dado el límite temporal acotado de esas explotaciones. Si bien no existe un rechazo hacia la minería, el fomento a la misma obtiene un porcentaje algo menor a otras actividades económicas y existe una percepción de que las empresas mineras generan contaminación.

En este sentido, según la evaluación de actividades económicas y emprendimientos productivos, realizada por el Responsable del Área Estratégica Mg. Miguel Oliva para el Informe Final entregado a la FADL, con base a un relevamiento realizado en trescientos hogares de San Julián en 2006; el turismo obtiene un porcentaje alto de encuestados que lo consideran beneficioso (46\%); la construcción obtiene altos porcentajes de evaluación beneficiosa (42\%); la ganadería obtiene un $29 \%$ de evaluación muy beneficiosa. Si bien no hay una proporción importante de opiniones negativas, el valor más elevado en la mención de actividades nada beneficiosas se observa en la minería con un $6 \%$. Por otro lado, al consultarse sobre los cambios que ocasionan en la comunidad las actividades mineras, si bien es considerada una actividad que genera empleo, al mismo tiempo, un $60 \%$ de los consultados señalan que produce contaminación (Agencia de Desarrollo San Julián, 2007).

Según el informe, se espera una ciudad con mayor desarrollo de infraestructura, básicamente en salud y calidad educativa. Se requiere la formulación de un plan de ordenamiento urbano. Se demanda mejor conectividad, básicamente aérea y marítima para mejorar la calidad de vida e impulsar actividades como el turismo. Se necesita mejorar la calidad de viviendas y el déficit habitacional. Uno de los ejes más importantes señalado en el Plan Participativo para el desarrollo económico de la comunidad y que además cuenta con un considerable apoyo de la opinión pública es la utilización de la energía eólica mediante la creación de un parque eólico, ya que San Julián es una de las zonas más favorables para ello.

Respecto al plan de ordenamiento urbano, en el informe final se mencionan como objetivos a desarrollar; la protección del patrimonio arquitectónico pionero en la localidad, la mejora de la calidad edilicia y consolidación del espacio urbanizado. La reelaboración de un código de edificación, zonificación del uso del suelo; la mejora en equipamientos educativos, instalaciones portuarias y construcción de una terminal pesquera. La complementación energética con generación local a partir de la construcción de un parque eólico. Reacondicionamientos de planta de tratamiento de residuos sólidos con factibilidad de relocalización y plan CIRSU (Cestión Integral de Residuos Sólidos Urbanos), y la rehabilitación del aeropuerto.

De todas las propuestas señaladas, se concretaron la zonificación del suelo, y la rehabilitación del aeropuerto que aún está en marcha; si bien ya está operativo, aunque orientado a la actividad minera. ${ }^{9}$ El reacondicionamiento de la planta de tratamiento de residuos sólidos fue realizado, además se adquirieron maquinarias y herramientas, y se promueve actualmente la separación de residuos domiciliarios. No obstante, el basural continúa en el mismo sitio, contiguo al mar, (con la contaminación que supone) y prácticamente sin espacio para el depósito de basura, con continuos focos de incendio que generan mayor contaminación. ${ }^{10}$

Por otro lado, aún no existe una normativa urbanística ni código de edificación. Se ha realizado una zonificación y uso del suelo, sin una planificación concreta, en este sentido, desde el propio Estado municipal se otorgaron parcelas para viviendas con falta de desarrollos de infraestructura (pavimento,

\footnotetext{
9 Sobre la reinauguración del aeropuerto en febrero de 2020, véase; https://winfo.com.ar/viajes/2020/02/aterrizo-el-primer-vuelo-de-lade-en-puerto-san-julian/

10 Sobre la gestión del basural, puede leerse en Diario Nuevo Día, consultado el 12 de marzo de 2021: https://www.eldiarionuevodia.com. ar/regional/info-general/2017/3/28/puerto-julincomenz-saneamiento-basural-37866.html
} 
cloacas, gas, agua) y en zonas en las que el suelo es inundable en épocas de lluvia, lo que ocasiona malestar en los vecinos; muchos de ellos fueron relocalizados en otros. ${ }^{11}$ Tampoco se ha legislado acerca de la protección del patrimonio arquitectónico. Así, unos cuantos edificios y casas pioneras de la localidad han sido vendidos y posteriormente derribados para la construcción de edificios privados.

En el Plan participativo se trazaron también propuestas en torno a la pequeña y mediana minería y las alternativas para uso artesanal. Entre los planes se destacan, crear un programa de unidad de negocio social, en el marco de la incubadora de empresas prevista; generar proyectos de industria local a partir del procesamiento de arcillas y evaluar la creación de una empresa público-privada para la fabricación de materiales de construcción sobre la base de yeso, caolines y arcillas.

En esta área, el taller de cerámica preexistente al proyecto CVSA, se continúa gestionado con fondos municipales, y no se generó una estructura asociativa con capital privado. El taller fue trasladado a otro edificio municipal tras reforma edilicia; y se vio modernizado con la donación de maquinarias de pequeña escala como hornos, herramientas y moldes, por parte de la empresa Odebrecht en el año 2009, mediante un programa de RSE. ${ }^{12}$ El resto del proceso permaneció de manera similar. La arcilla empleada procede FOMICRUZ como servicio de contraprestación con el municipio; el taller continúa produciendo piezas menores del tipo souvenirs para turistas y fabricadas por empleados municipales. No se ha logrado aumentar la escala, diversificar productos, allanar nuevos canales de comercialización, ni generar más empleo, habiéndose cerrado la escuela taller que existía y capacitaba a niños y adolescentes durante los años ochenta.

\footnotetext{
"Algunos vecinos que habían pagado un lote fiscal sin servicios de infraestructura básicos fueron relocalizados en 2016: https://www. mediaticadigital.com.ar/nota/14037-realizaran-reubicacion-de-terrenos-fiscales/, consultado el 12 de marzo de 2021.

12 Para más información ver https://www.odebrecht.com/es/odebrecht-inaugura-programa-de-apoyo-a-tejedoras-y-ceramistas-en-argentina, consultado el 20 de diciembre de 2020
}

Del mismo modo se realizaron propuestas en torno a la Gran Minería que tienen como propósito avanzar en un política local sustentable que, por un lado, oriente la institucionalización de procedimientos concretos de participación ciudadana especialmente al momento de finalización de la explotación y retiro de la empresa Cerro Vanguardia del territorio, y por el otro, que realmente opere sobre mecanismos que promuevan un mejoramiento en la distribución del ingreso a favor de las empresas locales proveedoras de servicios mineros. Según el informe del Plan, en 2007 solamente un 15\% de las contrataciones se realizaban con empresas regionales, dadas las condiciones de competitividad con empresas foráneas.

Referente a los proveedores locales, hace unos años, existe una Cámara de Proveedores Mineros de Santa Cruz (CAPROMISA), que promueve el compre local de la mano del Estado Provincial. Mediante la Ley provincial 3.616 del año 2018 se ha establecido como obligación para todas las empresas que operan en Santa Cruz, que el monto anual en contrataciones de obras, bienes, insumos o servicios con proveedores santacruceños inscriptos en un registro llamado RUPAE, no podrá ser inferior al 50\% del monto total contratado con todos sus proveedores. Actualmente, desde la Cámara señalan que no se cumple ese porcentaje de compre local, alcanzando solo un $29 \%$, y que las empresas mineras continúan argumentando que no están preparados para la industria. ${ }^{13}$ En este sentido, gran parte de las empresas locales ofrecen servicios menores, y productos con fácil nivel de sustitución.

Otro de los ejes proyectados en el Plan fue el sector turístico, con la finalidad de mejorar las condiciones para el desarrollo de la actividad turística y facilitar el surgimiento y la consolidación de capacidades institucionales y sociales que favorezcan un proceso de desarrollo endógeno. Actualmente, los operadores no están coordinados, y no existe un mecanismo que los agrupe y asesore por parte del

\footnotetext{
${ }^{13}$ Fernández, A. (20 de noviembre de 2019). RUPAE: Legislar para la sostenibilidad del desarrollo de las pymes locales. La opinión Austral. RUPAE: Legislar para la sostenibilidad del desarrollo de las pymes locales | La Opinión Austral (laopinionaustral.com.ar)
} 
Estado local. Asimismo, no existen estadísticas ni relevamientos al respecto. Por otro lado, la única agencia de turismo que se financió con fondos de la FADL a través de un crédito, se dedica al turismo emisivo y no al receptivo. Por otra parte, a pesar de producirse tres eventos anuales con potencial de visitantes; algunas de estas celebraciones se solventan con aportes de la FADL, sin generarse las herramientas que permitan una mayor captación de recursos de los visitantes durante su estadía en las fiestas.

El eje de pesca del Plan propone la creación del centro de estudios marítimos, laboratorios y museo de interpretación de la bahía. Impulsar el desarrollo y consolidar los sectores pesqueros artesanales y acuícolas de la ciudad. Proyecta también, la creación de una planta de elaboración de productos artesanal y acuicultura. Cenerar un programa de monitoreo de la calidad del agua y marea roja. Crear instrumentos de apoyo financiero y generar cadenas de eslabonamientos.

En relación con este punto, desde la UNPA se realizan estudios de calidad del agua; no obstante, no se ha concretado el laboratorio de marea roja, fundamental para el desarrollo de la acuicultura. Las actividades de capacitación que se han llevado adelante con pescadores artesanales devienen de las propias redes que establecen ellos con universidades del país, y con el Ministerio de Desarrollo Social, habiendo concretado pequeños proyectos en materia de capacitación y transferencia.

Por otro lado, se ha construido una terminal para pescadores artesanales con aportes procedentes del Fondo Fiduciario Unirse (que también se genera con fondos mineros) que controla la gobernación santacruceña, y el equipamiento de la misma ha sido financiado en parte por un proyecto presentado al Ministerio de Ciencia y Tecnología, y por la empresa municipal Fomento Pesquero San Julián, mediante la adquisición de equipamientos como cámaras de frío. Aún la misma se encuentra sin funcionar.

Actualmente, no se ofrecen otras ventanillas de financiación en la FADL, ni se imparte asesoramiento, ni otras fuentes diferentes de crédito que no sean aquellas vinculadas a los aportes de la misma FADL.
B. Destino de los aportes de la Fundación Agencia de Desarrollo

En abril de 2010, se firma el primer Acuerdo de RSE entre CVSA, el Municipio Local y la FADL; en el documento se señala que: "el Municipio prioriza la construcción colectiva del desarrollo sustentable para lo cual promovió en forma conjunta con CVSA la formación de la FADL, entidad encargada de la elaboración del Plan Director". CVSA se compromete a financiar con fondos resultantes de sus utilidades contables del ejercicio cerrado el inmediato anterior, el plan anual acordado con el municipio. El aporte no podrá ser inferior al monto resultante de ajustar el del año inmediato anterior por el coeficiente que resulte de cociente de la utilidad neta después de impuestos de ese mismo año, dividida por el mismo concepto del año anterior. (Acuerdos de RSE CV, Planes 2010-2019).

Las decisiones en la Agencia de Desarrollo, las toma por votación de mayoría simple un directorio compuesto por un representante de las siguientes instituciones: Cerro Vanguardia, Ejecutivo Municipal, Ejecutivo Provincial, Sociedad Rural, Cámara de Comercio, Universidad (UNPA), y dos concejales (mayoría y minoría) por el Honorable Concejo Deliberante.

A partir de examinar los planes, acuerdos y aportes entre municipio, CVSA y FADL, se realiza el siguiente análisis de datos que abarca desde el año 2010 al 2019. (Acuerdos RSE CV, Planes 2010-2019). También se consultaron fuentes periodísticas relativas al uso de los fondos.

En el año 2010 se definió como base un aporte de $\$ 3.000 .000$ (tres millones de pesos), el equivalente a US\$777.202, 07 según el tipo de cambio 1 US $\$=$ $\$ 3,86$. Durante el año 2010, la mayor proporción de los aportes fue destinada a la construcción de obras por parte del municipio que abarcaron un área infantil, un museo, una rotonda en el acceso de la ruta $\mathrm{N}^{\circ}$ 3, y equipamiento para divisiones del municipio. El restante fue destinado a la compra de una embarcación para una familia pescadora local, mediante la Línea de crédito Bicentenario. Si bien el proyecto 
se anunció por el intendente Gleadell14 como "desarrollo en el puerto y en sector pesquero", la embarcación finalmente opera en Caleta Olivia, (una localidad a 340 km al norte de San Julián) el negocio sigue siendo prácticamente familiar, y gran parte de su producción se comercializa a la empresa encargada de elaborar los menús diarios del Yacimiento Cerro Vanguardia.

Durante el año 2011, el monto alcanzó los $\$ 6.838 .887,02$, y se destinaron más del $55 \%$ de ellos a la remodelación de un cine-teatro, otro museo, y rotondas.

En el año 2012, los fondos del acuerdo de RSE fueron de \$7.484.640; y se destacan aportes en aumento para la línea de créditos productivos, y también destinados a diversas asociaciones locales, tanto de deportes como escuelas privadas de danzas, clubes, etcétera. Este año en las partidas se incluyeron fondos para fiestas locales, con pago de artistas, traslados, comidas, entre otros.

En 2013 el aporte de CVSA fue de \$8.506.636. La decana de la Universidad asumió la presidencia de la FADL. Con los fondos de esta entidad se restauró un edificio centenario que pertenece a la UNPA, denominado Hotel Colón, para convertirlo en un albergue estudiantil. El monto de aportes a las asociaciones locales aumentó. Asimismo, se financiaron nuevamente parte de las fiestas locales.

En el 2014 el acuerdo de RSE se firmó por $\$ 5.300 .197,20$, si bien con los aportes remanentes de 2013, y un compromiso de adelanto de fondos de 2015 por $\$ 3.000 .000$ (para compra de planta pesquera), ${ }^{15}$ se alcanzaron $\$ 11.708 .683,92$. El destino de los fondos va a estar marcado principalmente por la construcción para terceros; en este sentido, continuó la obra del albergue universitario $(\$ 4.310 .994,02)$, mientras se acometieron diferentes obras menores de otros albergues y ampliaciones de gimnasios de

\footnotetext{
Véase: https://www.nuestromar.org/antiguas/empresa-familiar-adquiere-buque-pesquero-merced-a-banco-solidario-municipal-san-julian/

${ }^{15}$ Sobre la compra de la planta pesquera véase: https://www.tiemposur. com.ar/nota/74013-se-concret\%C3\%B3-compra-de-planta-pesquera, consultado el 28 de diciembre de 2020
}

clubes locales. Por último, se ha aumentaron los fondos destinados a emprendedores, llegando a los $\$ 4.809 .027,46$.

En 2015, la cifra fue de $\$ 8.163 .783,19$, si bien con el remanente alcanzó \$11.158.975,49, o US\$ 1.224.914,98. El destino fue similar a los años anteriores, con obras a terceros (Universidad, clubes). En el ámbito productivo, mediante los créditos, se destaca un destino de $\$ 3.000 .000$ dirigido al sector agropecuario (para granjas de producción y huertas). En el sector salud, se compró aparatología y se destinó \$1.000.000 al proyecto GIRSU.

Durante 2016 se produce un cambio en la gestión de la FADL, debido al acto eleccionario de 2015, que ha significado un recambio de las figuras políticas que ocupan un lugar en el directorio. Los aportes este año, son de $\$ 7.072 .958,05$, el equivalente a US\$ $505.185,58$. Si bien, con el remanente del año anterior alcanzó los $\$ 9.752 .277,97$. Los fondos Ilegan hasta el nivel más bajo incluyendo el año 2010. Las partidas son similares en cuanto a educación, cultura y deportes. Aumentó el importe destinado a créditos de emprendedores.

En el año 2014, la FADL, había adquirido una planta pesquera a la firma Fishing World S.A. En 2016, con las nuevas autoridades, se decide crear mediante ordenanza 3231, la Sociedad Estatal Municipal Fomento Pesquero San Julián (FOPESAN). El destino de la planta es el alquiler a una empresa extranjera que captura centolla que exporta toda la producción, si bien ofrece empleo a los locales, es temporal y de baja calidad.

El año 2017, a pesar de persistir la devaluación del peso argentino, se percibe un importante incremento en el aporte de la empresa minera, pasandoa $\$ 24.781 .930,92$, o lo que es igual a US $\$ 1.574 .455 .59$. Las principales partidas fueron el acondicionamiento y ampliación del matadero local (obra que en cuatro años no se ha concluido y está en manos de la empresa constructora de uno de los directores de la FADL; $y$ que se ha vuelto a financiar con fondos de la FADL en 2020 por otros casi $\$ 30.000 .000$ con la misma empresa constructora, y habiendo 
sido elegido su propietario también, presidente de la FADL). ${ }^{16}$ El resultado de la licitación y reinicio de obras con el mismo empresario puede verse en la página oficial de la municipalidad (Municipalidad de Puerto San Julián, 2021).

Por otro lado, en 2017, se adquirieron tanques de combustible para la puesta en marcha del aeropuerto por $\$ 2.620 .564 .96$, se continuó con el programa de GIRSU, y conjuntamente se realizó un saneamiento del mismo, sumando un total de $\$ 4.711 .076 .55$. Por otro lado, la Universidad financió proyectos especiales con fondos de la FADL. La partida para emprendedores llegó a los \$4.845.650.

Durante el 2018, se percibe un nuevo incremento de las partidas, con un dólar a $\$ 20.03$, el aporte fue de $\$ 25.347 .537,90$, (o US\$1.265.478,68); que con el remanente del año anterior la cifra total asciende a $\$ 42.549 .823 .24$. Se destinaron a obras municipales, la instalación de los tanques combustible del aeropuerto y GIRSU. La partida para emprendedores fue de $\$ 2.056 .126$, 08 y se destinó $\$ 1.000 .000$ para equipamiento del sector ganadero.

En el año 2019, los aportes otorgados fueron de $\$ 50.836 .580,97$, con un tipo de cambio 1 US $\$=$ $\$ 43.93$. Sumado al remanente, alcanzaron los $\$ 73.773 .620,40$. En este año, se destinaron fondos para pagar la sentencia del municipio por la titularidad del ex frigorífico Swift por $\$ 15.000 .000$, con la que podrá ampliar el radio del ejido urbano; y luego se prolongaron las obras en GIRSU y aeropuerto. También la Universidad fue beneficiaria de una partida importante para la recuperación arqueológica de Florida Blanca por \$2.396.500.

\footnotetext{
${ }^{16}$ La primera Licitación por la Primera Etapa fue concedida en 2018 a la firma Michudis (Director de la FADL por la Cámara de Comercio, siendo desde 2020 el presidente de la FADL). https://santacruzuno.com. ar/2018/09/14/se-licito-la-obra-del-matadero-municipal/, consultado 12 de marzo de 2020. El 5/12/2019 se labró acta de neutralización de obra por el tiempo en el que se había extendido y por los costos; por lo que se decidió entonces rescindir el contrato con la empresa (Resolución 81/2020 HCD). Posteriormente, mediante Ordenanza 3440 el 28/09/2020 se llamó nuevamente a Licitación Pública N²/2020 para el reacondicionamiento del matadero. Resulta adjudicada, mediante Resolución 3822/2020, de nuevo a la empresa Michudis, por una suma total de $\$ 29.659 .422,81$, con fondos de RSE de la Fundación Agencia de Desarrollo. (Resolución 3822/2020 Municipalidad de Puerto San Julián).
}

En diciembre de 2009, el Municipio, CVSA y la Agencia de Desarrollo firman un nuevo dispositivo legal por medio del cual crean la Línea Crediticia Bicentenario. La Agencia de Desarrollo comienza a gestionar fondos de terceros para financiar proyectos productivos y de servicios, seleccionando los beneficiarios y las condiciones de otorgamiento. El Municipio mediante el Banco Solidario es el ejecutor del reembolso (Mansilla, 2014).

Dentro de estos créditos se financiaron proyectos que van desde la compra de embarcaciones, maquinaria metalúrgica, herramientas, lavanderías, panificadoras, restaurantes, imprenta, construcción, invernaderos, hasta peloteros, gimnasios y salones de fiestas. Los créditos son a tasas muy bajas respecto a las de las entidades bancarias y con cuotas fijas. Los objetivos de los créditos, son la generación de empleo y que el emprendimiento sea perdurable, y que con el reembolso, se forme un recupero que permita conceder más créditos.

Analizando la situación de los créditos otorgados, son escasos los emprendimientos que han logrado generar empleo y ser rentables. La tasa de mora en el pago es muy alta; algunos terminan en etapa judicial, y gran parte de los beneficiarios no han podido continuar con su empresa o no han encontrado canales de comercialización para sus productos. Los que sobresalen con éxito son aquellos que tienen establecido el circuito comercializador directo con las mineras, aunque la dependencia hacia estas marca su vulnerabilidad en el largo plazo. 
Gráfico 1. Aportes de RSE de CVSA a la FADL desde 2010 a 2019

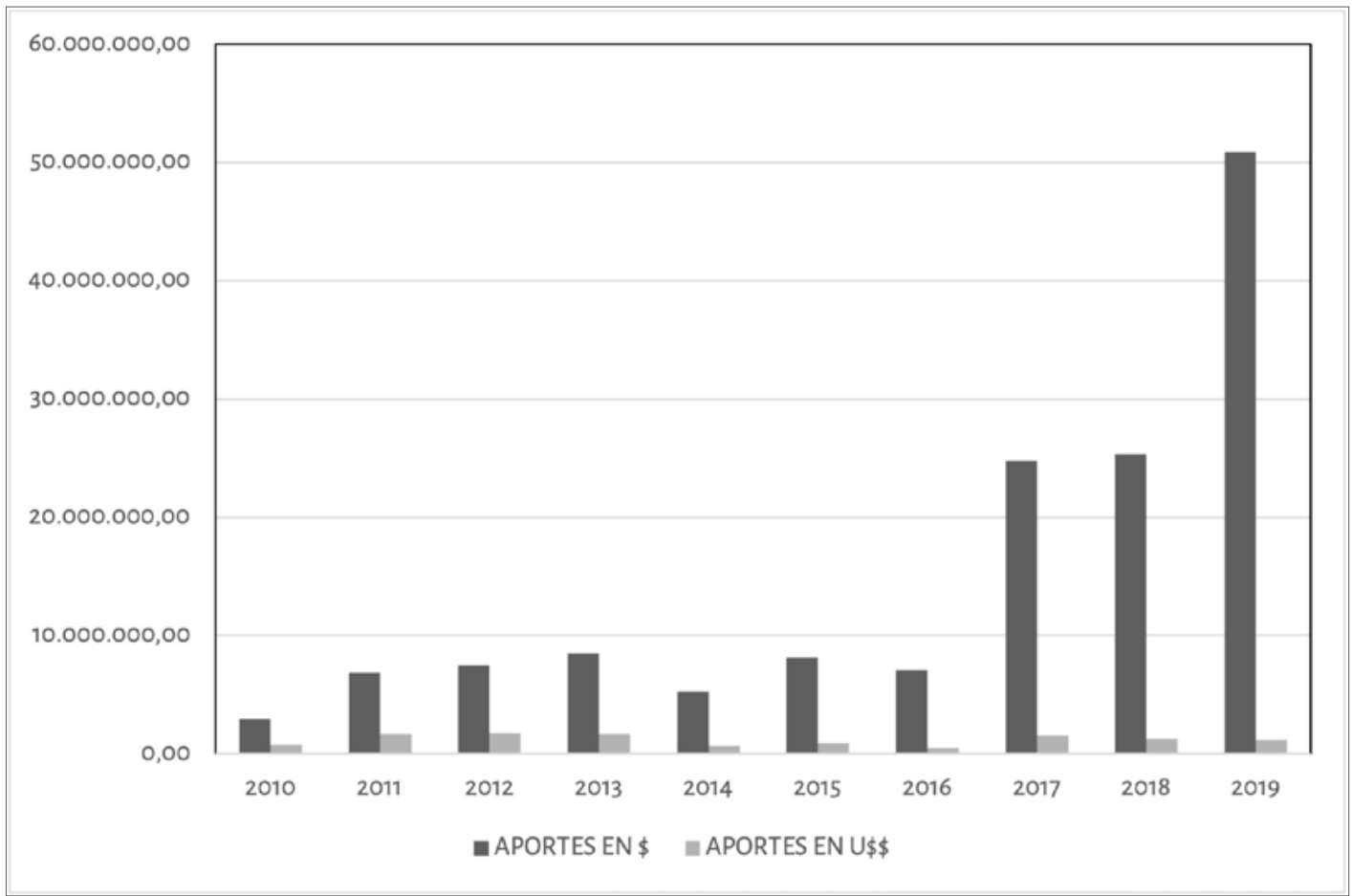

Fuente: según Convenios de RSE firmados entre CVSA, Municipio San Julián y FADL.

Gráfico 2. Destino de los aportes de la FADL desde 2010 a 2019.

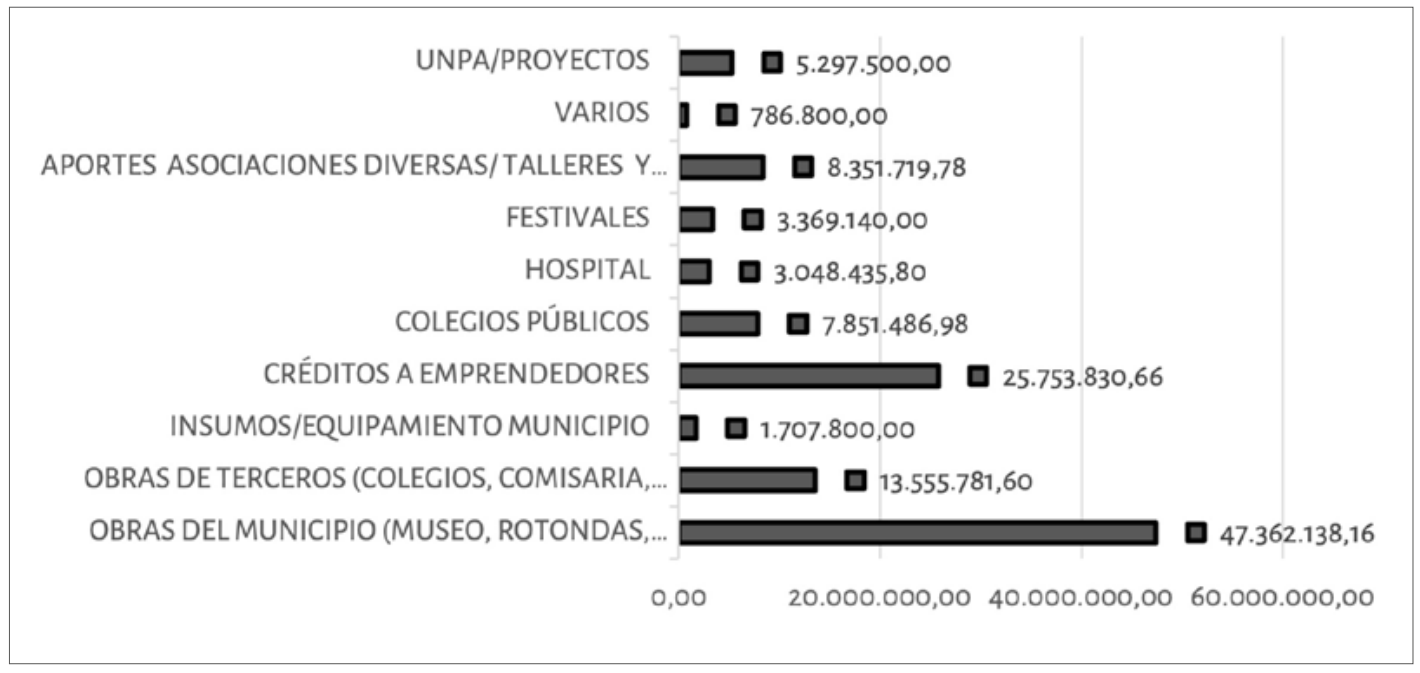

Fuente: según datos de los Planes anuales firmados por la FADL (2010-2019). 


\section{Conclusiones}

El Plan Participativo fue propicio para una discusión y toma de posiciones respecto al futuro de San Julián por gran parte de su sociedad, que como se señaló anteriormente, fue adherido por treinta y ocho organizaciones públicas, privadas y de la sociedad civil de San Julián. Uno de los problemas a resolver implicaba poner en marcha otras actividades económicas que generaran empleo. Específicamente se abordaban las necesidades que existían en ese entonces, y se vislumbraba el cierre del yacimiento como algo que había que amortiguar antes de que llegara el 2020.

En el análisis realizado se han enumerado las propuestas del Plan Participativo, de las que luego no hubo seguimiento, planificación ni evaluación. De todos los programas formulados en 2007-2008, la puesta en marcha del aeropuerto, y el acondicionamiento del basural son de las pocas que responden parcialmente al Plan.

El rol de la FADL se ha visto relegado a una suerte de financiera para gran parte de los entes, sectores sociales y del propio Estado local, más que a su cometido de preparar a la localidad para un próximo futuro sin minería, mediante estrategias, planes y programas que generen empleo a través del impulso de otros sectores económicos. ${ }^{17}$ La FADL ha generado una nueva dinámica clientelista entre la empresa minera y cierta parte de la comunidad, a cambio de legitimidad social, evitando de esta manera cuestionamientos sobre la actividad minera. Por otro lado, Torunczyk (2016) señala que: "La repartición de fondos no ha ayudado a crear un nuevo espacio de participación social, sino que reforzó el poder del gobierno local desde 2003 dándole nuevos recursos económicos que han permitido su reelección en 2007 y $2011^{\prime \prime}$ (p. 5).

\footnotetext{
${ }_{17}$ Tal como lo señala la misma empresa en su página Web: "en el año 2004, la Compañía propuso la creación de un ente en Puerto San Julián que se ocupe de impulsar el desarrollo de actividades económicas sustentables. Cerro Vanguardia (9 de marzo de 2021) Relato histórico sobre la Agencia. www.cerrovanguardia.com.ar/responsabilidad-social/relato-historico-sobre-la-agencia/
}

Igualmente, dentro del directorio de la FADL, que es el órgano encargado de decidir el destino de los aportes mineros, se observa un conflicto de intereses en el ejercicio de sus funciones. Algunos de sus directores son políticos y empresarios que proveen al Estado local y a las mineras; por un lado deciden qué destino dar a los fondos de la FADL y por otro, participan como empresarios en las licitaciones que son financiadas con esos mismos fondos y con base a esas decisiones. Así, la FADL fortalece el poder de influencia con el que cuentan determinados empresarios y políticos locales, sin ser cuestionados política ni socialmente.

Muchas de las dificultades en alcanzar las metas propuestas se justifican con las recurrentes crisis económicas (inflación y devaluación del peso respecto al dólar) que hacen imprevisibles los cambios en los proyectos. Otra de las problemáticas que surgen, es que los programas de las políticas decididas no se establecen a largo plazo ni existen evaluaciones de los mismos, ni muchos de ellos están eslabonados o coordinados; generalmente, se interponen más las preferencias que otorga cada intendente para solicitar el uso de los aportes de la FADL, que las propuestas del Plan Participativo, generándose poca o escasa continuidad en algunos de los proyectos que ya están en curso. La finalidad inicial del uso de los fondos de la FADL es alterada y se destina para resolver gastos corrientes que no pueden solventar las instituciones, el municipio, y entes de la provincia.

Algunos autores señalan que:

No se dibuja un modelo productivo e institucional de recambio, más bien parece responderse a demandas puntuales y de coyuntura, que tienen la función de mostrar una preocupación por el presente, que no puede ocultar que el financiamiento y el sostén financiero y político que la FADL requerirá, puede no estar disponible cuando más acuciante y urgente será su necesidad (Andrade et al, 2011, p. 97).

Finalmente, después de 2007-2008, no se realizaron más reuniones ni consultas vecinales sobre 
la actividad de la FADL o acerca de las políticas públicas puestas en marcha. Actualmente, gran parte de la población observa con preocupación el futuro socioeconómico de San Julián, reconociendo que la minería llegará a su fin y que la localidad no está preparada para ello. Acercándose al futuro ineludible, durante 2019, la empresa comunicó dos novedades: la venta de CVSA y el cierre de mina, señalando como fecha el 2025. ${ }^{18}$

Como señala Banerjee (2008):

¿Qué le pasará a una comunidad local que es completamente dependiente para su bienestar económico, social y medioambiental de una empresa multinacional una vez que ésta decide mover su ubicación por motivos económicos? Las corporaciones no tienen la capacidad de asumir el papel de los gobiernos en la contribución al bienestar social simplemente porque su función básica está impulsada inherentemente por las necesidades económicas. Los mercados por muy eficientes que sean en la fijación de precios, no pueden asegurar que las corporaciones siempre actuarán en interés de la sociedad (p. 74).

\footnotetext{
${ }^{18}$ Más información en Agencia Opi Santa Cruz, 18 de marzo, 2019. A confesión de parte, relevo de pruebas. Así planteó Anglo Cold el cierre de mina de Cerro Vanguardia. OPI Santa Cruz. Recuperado de: https:// opisantacruz.com.ar/2019/03/18/a-confesion-de-parte-relevo-depruebas-asi-planteo-anglo-gold-el-cierre-de-mina-en-cerro-vanguardia

Respecto a la venta de CVSA, véase El Cronista, 20 de febrero, 2019. AngloGold Venderá su participación en la mina local Cerro Vanguardia. El Cronista. Recuperado de:https://www.cronista.com/apertura-negocio/ empresas/AngloGold-vendera-su-participacion-en-la-mina-local-Cerro-Vanguardia-20190219-0008.html
}

\section{Referencias}

Andrade, L. (2005). Sociología de la desertificación. Los productores ovino-extensivos en la Meseta Central Santacruceña. Miño y Dávila/UNPA. Bs. As.

Andrade, L. (2018). Relevamiento socio-económico, demográfico yocupacional de Puerto San Julián. UNPA/ ADL.

Andrade, L.; Álvarez, R.; Bedacarratx, V. (2011). Aporía del desarrollo o ¿Qué desarrollo después de la minería en la zona centro de Santa Cruz? Párrafos Geográficos. ISSN 1853-9424.

Antonelli, M. (2009). Minería transnacional y dispositivos de intervención en la cultura La gestión del paradigma hegemónico de la "minería responsable y desarrollo sustentable". En: Maristella (ed.), Svampa y Mirta A. Antonelli. -1a. ed. Minería transnacional, narrativas del desarrollo y resistencias sociales. Buenos Aires: Biblos. ISBN 978-950-786709-5

Banerjje, S. (2008). Corporate Social Responsibility: The Cood, the Bad and the Ugly. Critical Sociology,34 (1) 51-79. SACE Publications (Los Angeles, London, New Delhi and Singapore). DOI: 10.1177/0896920507084623.

Bechtum, A. (2018). La minería a gran escala en la Patagonia Sur: El caso de Cerro Vanguardia y la localidad de Puerto San Julián, Santa Cruz. Identidades, (14), Año 8, 154-174.

Bertranou, J. (2019). El seguimiento y la evaluación de políticas públicas. Modelos disponibles para producción de conocimiento y mejorar el desempeño de las intervenciones públicas. MILLCAYAC - Revista Digital de Ciencias Sociales, 6(10), 151-188. SIPUC. FCPyS. UNCuyo. Mendoza

Cepal. (2006). La responsabilidad social empresarial: ¿sólo un discurso? Fuertes, F., Goyburu, M., Kosacoff, B. (Eds). Naciones Unidas.

Cepal. (2015). La planificación participativa para lograr un cambio estructural con igualdad. Sandoval, C., Sanhueza, A., Williner, A. Naciones Unidas.

El Cronista. (20 de febrero de 2019). AngloGold Venderá su participación en la mina local Cerro Vanguardia. El Cronista. https://www.cronista.com/ apertura-negocio/empresas/AngloCold-vendera-su-participacion-en-la-mina-local-Cerro-Vanguardia-20190219-0008.html 
Fernández, A. (20 de noviembre de 2019). RUPAE: Legislar para la sostenibilidad del desarrollo de las pymes locales. La opinión Austral. https://RUPAE: Legislar para la sostenibilidad del desarrollo de las pymes locales | La Opinión Austral (laopinionaustral.com.ar)

Godfrid, J. (2015). El consenso de Washington y su influencia en la política pública argentina. Un análisis de caso sobre las transformaciones del marco regulatorio en el sector minero argentino 1990-2013. Espacio Abierto, 24(2), 255-273.

Huwiler, L., Duarez, J., Godfrid J. (2015). Expansión minera y protesta social en Argentina y Perú. Investigaciones Sociales, 19 (35), 169-186. https://doi. org/10.15381/is.v19i35.12126

Indec. Instituto Nacional de Estadísticas y Censos. (s.f). Censos 1991, 2001 y 2010. https://www.indec.gob.ar/indec/web/Nivel3-Tema-2-41

Ley 24.196/93 de 24 de abril de 1993, sobre Inversiones Mineras. Boletín Oficial del 24-may-1993. http://servicios.infoleg.gob.ar/infoleglnternet/ anexos/0-4999/594/norma.htm

Ley 24.498/95 de 14 de junio de 1995, de Actualización Minera. Boletín Oficial del 19-Julio-1995. http://argentinambiental.com/legislacion/nacional/ley-24-498-modificacion-del-codigo-mineria/

Ley 3.616/18 de 13 de septiembre de 2018, Creación del Registro único de Proveedores de Actividades Económicas en el ámbito de Ministerio de la Producción, comercio e Industria de la Provincia de Santa Cruz. Boletín Oficial del 23-oct-2018. http:// www.saij.gob.ar/3616-local-santa-cruz-creacion-registro-unico-proveedores-actividades-economicas-ambito-ministerio-produccion-comercio-industria-provincia-santa-cruzIpzoo03616-2018-09-13/123456789-oabc-defg616-3000zvorpyel?utm_source=newsletter-semanal\&utm_medium=email\&utm_term=semanal\&utm_campaign=ley-provincial

Mansilla, C. (2014). Planificación, participación y sustentabilidad del desarrollo en Puerto San Julián. Desafíos de la política social. Revista de estudios regionales y mercado de trabajo, (10), 125-153
Municipalidad de Puerto San Julián. (13 de enero de 2021). Inicio la primera etapa de la obra de ampliación de refacción del matadero municipal. Facebook. https://www.facebook.com/MunicipalidadPuertoSanjulian

Opi Santa Cruz. (18 de marzo de 2019). A confesión de parte, relevo de pruebas. Así planteó Anglo Cold el cierre de mina de Cerro Vanguardia. OPI Santa Cruz: https://opisantacruz.com.ar/2019/03/18/aconfesion-de-parte-relevo-de-pruebas-asi-planteo-anglo-gold-el-cierre-de-mina-en-cerro-vanguardia

Peinado, G. y Saguier, M. (2014). Minería transnacional $y$ desarrollo en el Kirchnerismo. FLACSO-ISA Joint International Conference Clobal And Regional Powers In A Changing World, Buenos Aires, Julio 2014.

Rofman, A. (2004). Actualización crítica del enfoque del desarrollo sustentable. Mundo Urbano, (15).Universidad Nacional de Quilmes. http:// www. mundourbano.unq.edu.ar/index.php/ ano-2002/57-numero-15/93-3-actualizacion-critica-del-enfoque-del-desarrollo-sustentable

Schinelli, D., Vacca, C., Williams, M. (2011). El empleo rural en Santa Cruz: Situación de coyuntura o crisis estructural. Revista de estudios regionales y mercado de trabajo, (7), 37-58.

Svampa, M. (2008). Argentina: Una cartografía de las resistencias (2003-2008). Entre las luchas por la inclusión y las discusiones sobre el modelo de desarrollo. Revista Osal, (24),

Torunczyk Schein, D. (2015) Soberanías en conflicto: minería transnacional, política subnacional y movimientos socioambientales en Argentina. Université Du Québec À Montréal.

Torunczyk Schein, D. (2016). The socio-political dynamics of transnational mining in Argentina: The cases of Puerto San Julián and Esquel in Patagonia. The Extractive Industries and Society, 3(4), 10671074. http://dx.doi.org/10.1016/j.exis.2016.08.001 


\section{Otras Fuentes Documentales}

Agencia de Desarrollo San Julián. (2007). Análisis de condiciones del entorno y expectativas sobre el presente y futuro de San Julián. http://agenciadesarrollosj.gob.ar/analisis-de-condiciones-de-entorno-y-de-expectativas-sociales1/

Cerro Vanguardia -Anglo Cold Ashanti-. (29 de diciembre de 2020). Relato histórico sobre la Agencia. www.cerrovanguardia.com.ar/responsabilidad-social/relato-historico-sobre-la-agencia/

Plan Participativo de Desarrollo Sustentable de Puerto San Julián y su zona de Influencia. (2008), Documento Final, FADPS]-MPS], Puerto San Julián, Santa Cruz. http://agenciadesarrollosj.gob. ar/plan-participativo/

Testimonio del Estatuto Social de la Fundación Agencia de Desarrollo San Julián, Santa Cruz. Ministerio de Cobierno. (26 de Junio de 2006). Inspección Ceneral de Personas Jurídicas.

Acuerdos de Responsabilidad Social Empresarial (RSE) de Cerro Vanguardia. Planes 2010-2019. Puerto San Julián, Santa Cruz. 